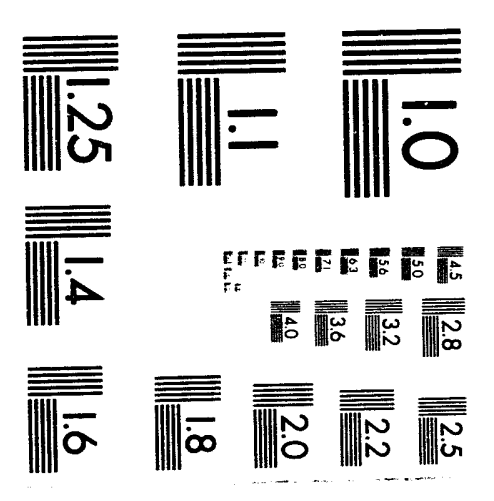



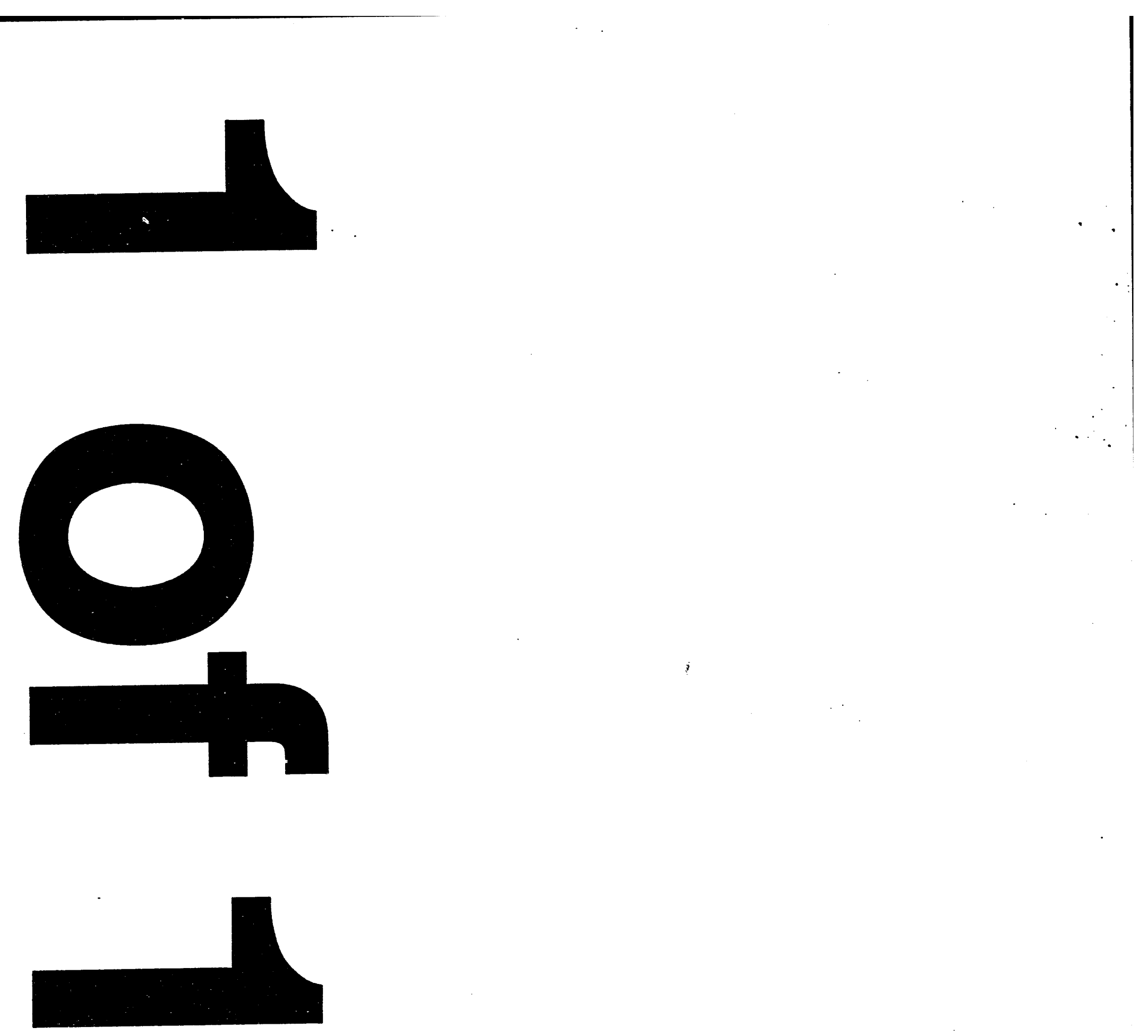


\title{
EXTENSIVE UTILIZATION OF ARGONNE PREMIUM COALS IN RESEARCH
}

\author{
Karl S. Vorres
}

\author{
Chemistry Division, Argonne National Laboratory
}

Over 200 basic research papers have now resulted from fundamental studies of the 14,000 samples of the Argonne Premium Coals that have been shipped to coal scientists in this country and abroad. This research community has recognized the unprecedented opportunity that the premium samples afford to compare, contrast, and correlate experimental information obtained in different laboratories on coal samples that are uniform, stable, and in long-term supply. Indeed, a number of groups are using this set of materials exclusively in their basic coal research programs. The selection, collection, processing, packaging, characterization, and shipping have been done under the supervision of Dr. Karl S. Vorres at Argonne National Laboratory with the support of the Division of Chemical Sciences. The coal-processing facility is unique in the world for its ability to process ton-sized coal samples into sealed, uniform, 5- or 10-g lots in pyrex ampoules, completely under nitrogen kept below 100-partsper-million oxygen.

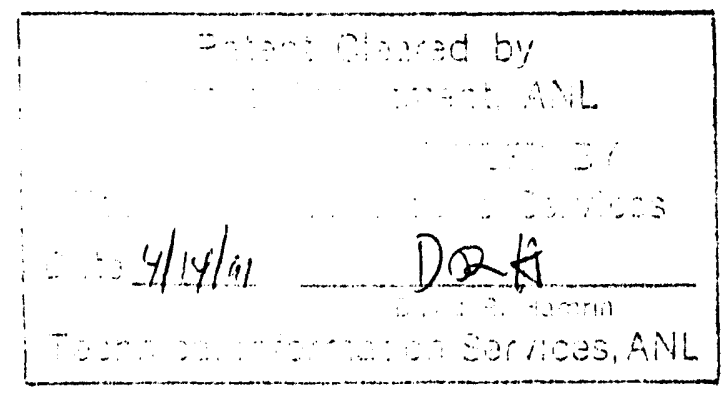

\section{DISCLAIMER}

This report was prepared as an account of work sponsored by an agency of the United States Government. Neither the United States Government nor any agency thereof, nor any of their employees, makes any warranty, express or implied, or assumes any legal liability or responsibility for the accuracy, completeness, or usefulness of any information, apparatus, product, or process disclosed, or represents that its use would not infringe privately owned rights. Reference herein to any specific commercial product, process, or service by trade name, trademark, manufacturer, or otherwise does not necessarily constitute or imply its endorsement, recommendation, or favoring by the United States Government or any agency thereof. The views and opinions of authors expressed herein do not necessarily state or reflect those of the United States Government or any agency thereof. 


\title{
EXTENSIVE UTILIZATION OF ARGONNE PREMIUM COALS IN RESEARCH
}

\author{
Karl S. Vorres \\ Chemistry Division, Argonne National Laboratory
}

The Argonne Premium Coal Sample Program has provided the samples which resulted in over 200 (225 at the time of this writing) references in various scientific journals and books describing results of work with this unique set of samples. The work has appeared in each of the major journals devoted to basic research in coal science. The publications have appeared essentially over a fouryear span. Figure 1 shows the number of publications which have appeared for each of the years since the inception of the program. The first of the samples was not available until April 1985. The complete set was not available until March of 1987.

These publications include contributions from laboratories in each of the continents doing coal research except Africa and South America. A bibliography has been prepared and distributed to each of the sample recipients, and is updated on a quarterly basis. An index is also available so that references can be found by author, subject, journal, or coal used. A primal reference has recently appeared in Energy \& Fuels (an American Chemical Society publication) which will be used in future publications to facilitate retrieval of references and augmentation of the bibliography.

The Premium Coal Sample Program has been carried out to provide the best possible samples of a very limited set of U.S. coals for basic coal research. These samples were carefully selected, collected, transpored, processed, packaged, and analyzed. Individual ampoules were sealed under nitrogen in glass to preserve the uniformity of the initial 15,000 ampoules of each sample and an additional 60,000 that can be prepared from the reserves that are held in five-gallon carboys.

A series of eight coals has been prepared to represent the range of carbon, hydrogen, sulfur, and other elemental contents in U.S. coals. These samples have been thoroughly characterized and are periodically checked for stability. The ampoules of pyrex glass give an extremely secure seal and have been found to protect the integrity of each sample since the time of sealing. 
To date more than 500 (513 at the time of this writing) shipments totaling almost 14,000 ampoules have been made to lavoratories on almost every continent (see Figure 2).

A Users Handbook, supplied to every user, provides a unique information source to all recipients of the samples. The Handbook includes a description of the samples from selection through packaging, extensive analytical data, the extensive bibliography of research done indexed according to author, subject, coals used, and journal. A literature summary gives a review in sufficient detail for work in 17 categories of research to permit a rapid understanding of the state of research with these materials. This summary is being updated by a group of experts drawn from the different fields to maintain an understanding of the state of research in each area. The samples have been adopted in a number of laboratories as the only samples to be used in their basic research programs. The future of basic coal research will be shaped by the use of these samples.

A quarterly newsletter is prepared and distributed to each of the sample recipients without charge. This newsletter keeps the users aware of the most recent publications so the bibliographic information is kept as current as possible.

Periodic symposia on research with the Argonne Premium Coal Samples are presented before the Fuel Chemistry Division of the American Chemical Society. These symposia provide a forum for recent work and an opportunity to publish this work in the Preprints of the Fuel Chemistry Division. Four of these symposia have been held and have had participation from an international community of research workers.

The periodic symposia have been not only general but there has also been one devoted to nuclear magnetic resonance studies of these samples. 


\section{Number of Publications for APCSP Through Oct. 1990}

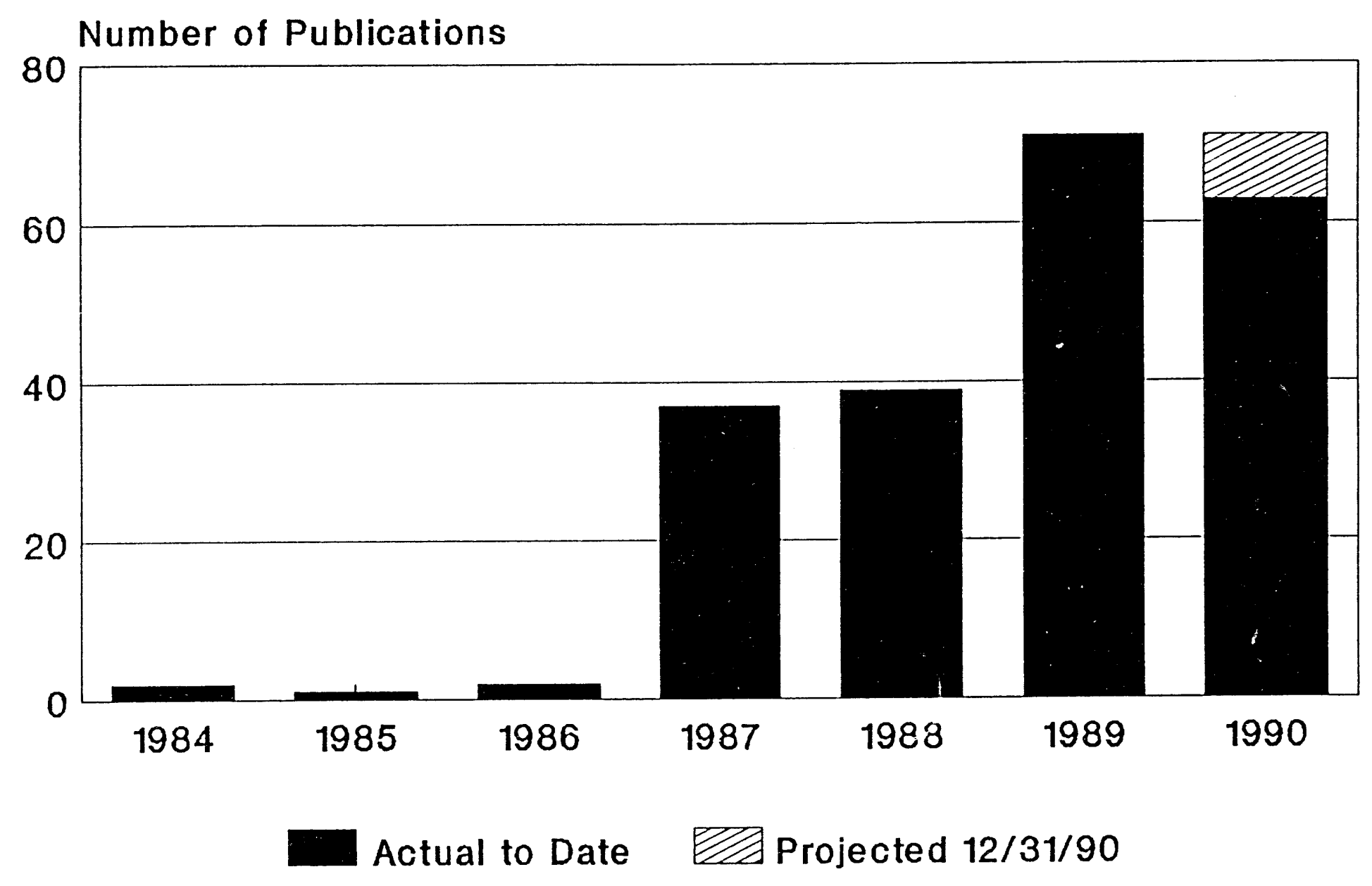




\section{Total Ampoule Shipments through October, 1990}

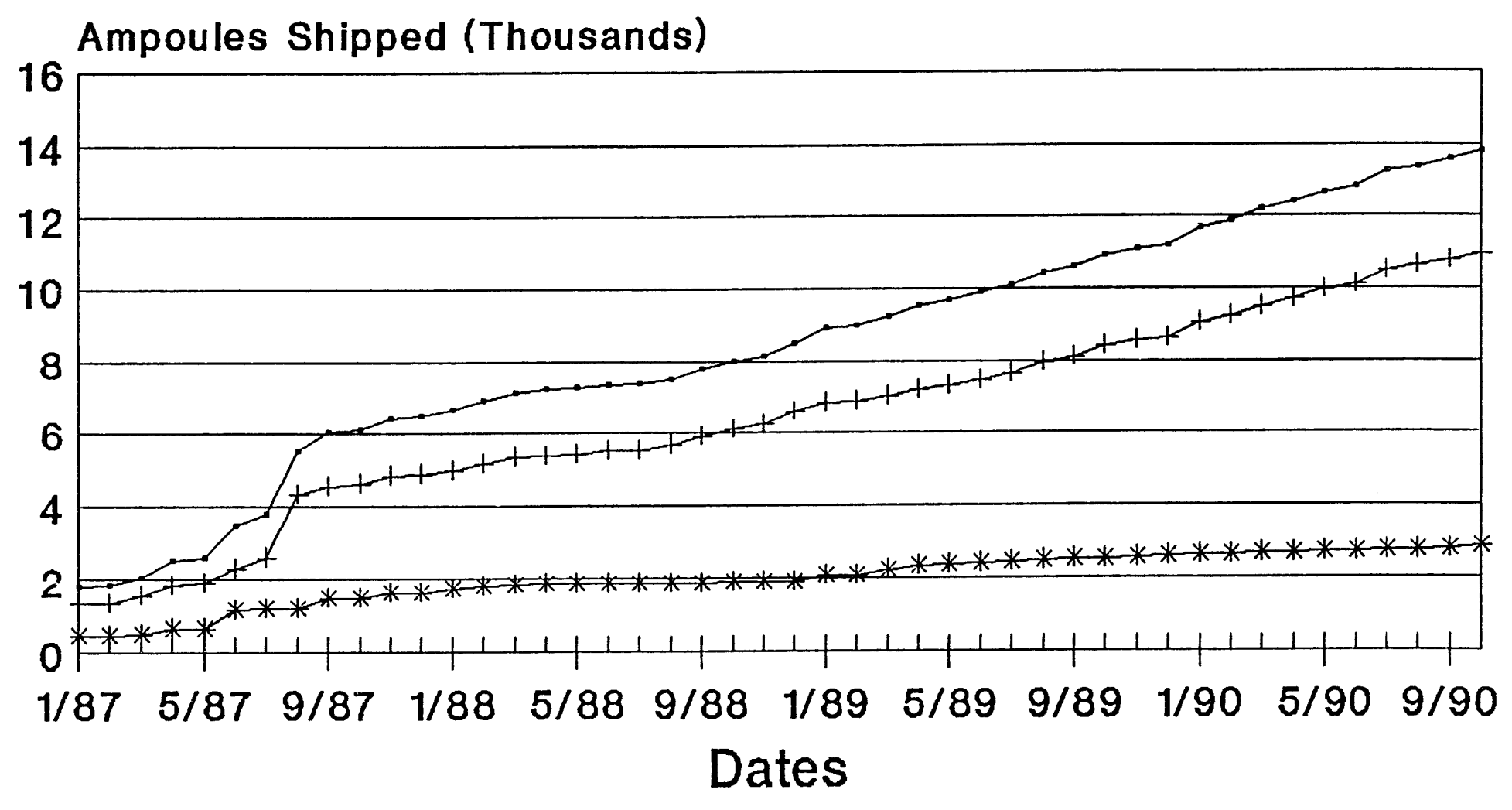

- Total +-100 Mesh * -20 Mesh

Figure 2 

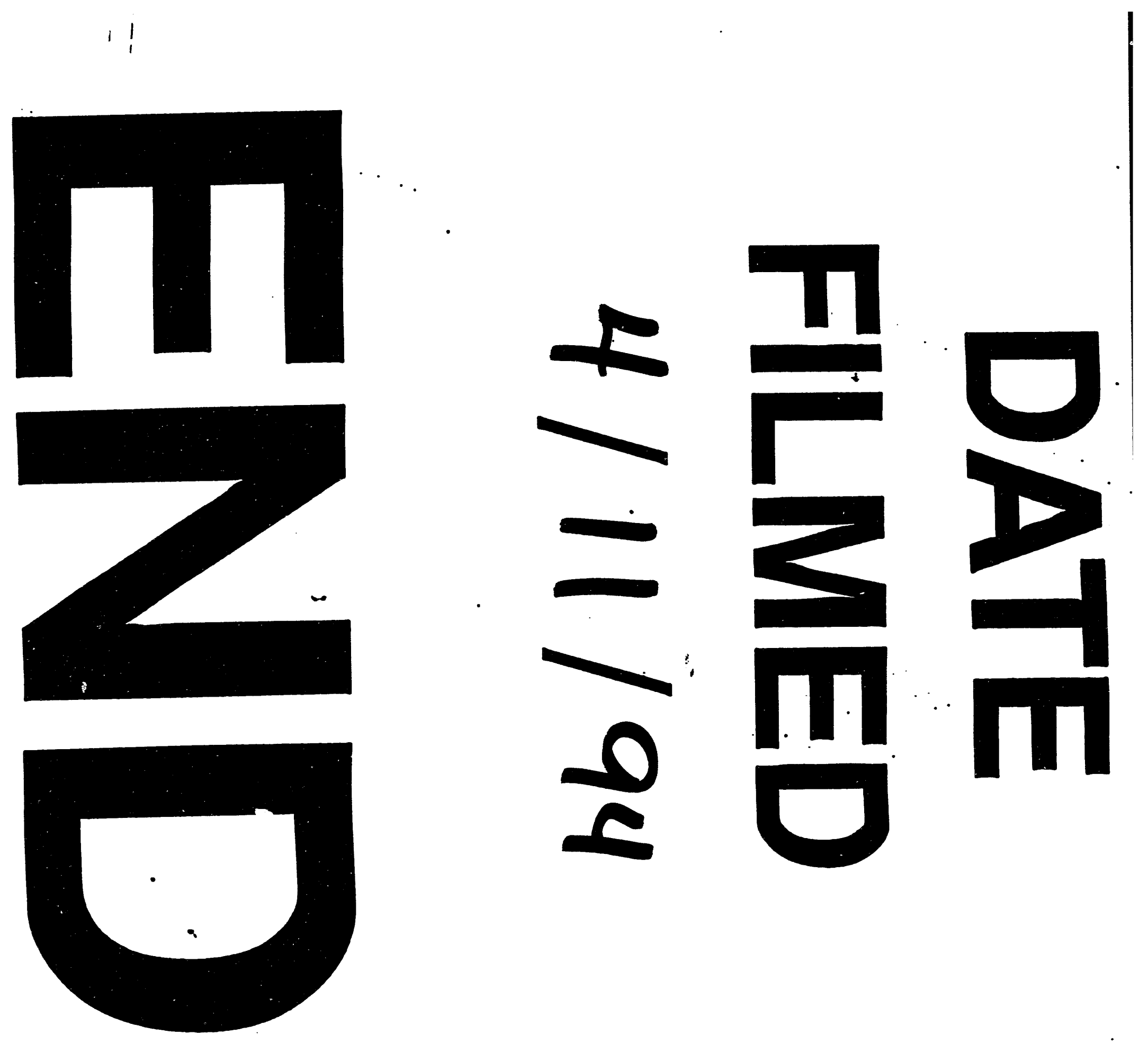
2

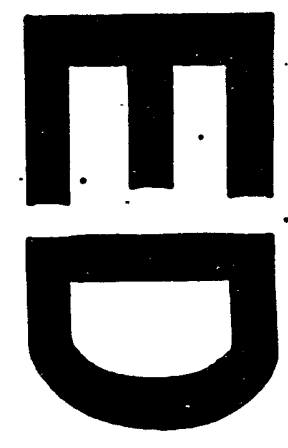


